\title{
The Harm We Do: The Environmental Impact of Medicine
}

\author{
Julia Schoen, $\mathrm{MS}^{1 *}$, Vineet Chopra, MD, MSc1,2 \\ 'The University of Michigan School of Medicine, Ann Arbor, Michigan; ${ }^{T}$ The Division of Hospital Medicine, Michigan Medicine, Ann Arbor, Michigan.
}

While often unseen and infrequently discussed, the environmental impact of hospital systems and healthcare providers is substantial. However, some US hospitals and healthcare systems have developed innovative approaches to reduce their environmental impact while reducing costs. In this perspective, we discuss how hospitalists may support ongoing environmental efforts through education and awareness, measurement and amelioration, public reporting, and individual actions. Given the extent of healthcare's impact on the environment, the benefits of interventions, and the link between hospitalists and hospitals, We must minimize the harm we do. Journal of Hospital Medicine 2018;13:353-355. Published online first February 27, 2018. @ 2018 Society of Hospital Medicine

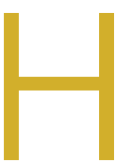

ealthcare is a "dirty" business with widespread effects on the environment. In the US, healthcare is estimated to generate $9.8 \%$ of our greenhouse gases and $9 \%$ of our particulate matter emissions. ${ }^{1} \mathrm{Haz}-$ ardous wastes must be incinerated, emitting carbon dioxide, nitrogen oxides, and volatile substances into the atmosphere. ${ }^{2}$ Similarly, hospitals are responsible for $7 \%$ of commercial water use in the US. ${ }^{3}$ Conventional water treatment systems are not designed to remove heavy metals, pharmaceuticals, and disinfectants in hospital wastewaters; these compounds have been detected in rivers and streams throughout the US. ${ }^{4,5}$ Furthermore, pharmaceutical compounds such as antibiotics, anti-epileptics, and narcotics have even been isolated in our drinking water. ${ }^{5}$

As hospitalists, we are the directors of inpatient care, yet we only witness brief moments in the lives of our patients and the products we use for their care. For example, we are unaware of particulate matter emissions needed to power an extra imaging study or the contribution of unused materials to a growing landfill. However, pollution, including that from our clinical practice, is detrimental to human health in many ways. Exposure to particulate matter and toxic wastes has been linked to increased rates of reproductive and developmental disorders, cancer, and respiratory disease. ${ }^{6}$ Particles $<2.5 \mu \mathrm{m}$ in diameter can diffuse through alveoli into the bloodstream, contributing to heart disease, stroke, and lung disease. ${ }^{7}$ Climate change has been linked to a wide range of adverse cardiovascular, respiratory, infectious, and mental health outcomes. ${ }^{8,9}$ These examples of the health impacts of pollution are illustrative but not exhaustive.

Address for correspondence: Julia Schoen, MS; University of Michigan Medical School, 3852 E Medical Center Drive, Ann Arbor, MI 48109; E-mail: jhschoen@med.umich.edu

Received: September 15, 2017; Revised: December 11, 2017 . Accepted: December 17, 2017

2018 Society of Hospital Medicine DOI 10.12788/jhm.2947
The environmental impact of US healthcare accounts for an estimated 470,000 disability-adjusted life years lost; this figure is on par with the burden of preventable medical errors. ${ }^{1}$ Clearly, change is necessary at all levels in the healthcare system to address our impact on human health. Fortunately, healthcare systems and hospital administrators have begun to address this issue. This perspective describes sustainability efforts in hospitals and healthcare systems and seeks to motivate hospitalists to build upon these efforts.

\section{EFFORTS BY HOSPITALS AND HEALTHCARE SYSTEMS}

With the ability to affect change from the top down, health systems are playing an important role in healthcare's environmental sustainability. Ambitiously, Kaiser Permanente outlined eight environmental stewardship goals, which include becoming net carbon positive and recycling, reusing, or composting $100 \%$ of their non-hazardous waste by $2025 .^{10}$ The Cleveland Clinic has pledged to become carbon neutral within the next 10 years. ${ }^{11}$ Other healthcare systems may follow suite. Many "green" interventions aimed at reducing waste and pollution also protect population health and reduce hospital operating costs.

From 2011 to 2015, a group of Boston Hospitals decreased energy use by $9.4 \%$ compared with a historical growth of $1.5 \%$ per year and saved over 15 million dollars. ${ }^{12}$ Similarly, Virginia Mason reduced landfill waste by reprocessing single-use medical devices, thereby decreasing purchasing costs by $\$ 3$ million. ${ }^{13}$ As part of a regional campaign to protect the St. Croix River, Hudson Hospital and Clinic in Wisconsin saved over $\$ 20,000$ with new recycling and waste reduction programs. ${ }^{13}$ Notably, these programs not only benefit hospitals but also patients and payers by reducing costs of care.

\section{ROLE OF THE HOSPITALIST}

These examples illustrate that a greener healthcare industry is achievable. Despite the potential benefits, sustainability efforts in US hospitals are the exception, not the rule, and the 
diffusion of such innovations must be encouraged from within.

In addition to the moral case for environmentally sustainable healthcare, ${ }^{14,15}$ such efforts can also improve our quality of care. The conversation around healthcare waste has focused on costs. Yet, examining our waste from a new perspective may reveal new ways to increase the value of patient care while protecting population health. Our communities and families are not immune to the health impacts of pollution, including that generated by our industry. However, predicted effects of climate change including altered patterns of vector-borne disease and frequent hurricanes and forest fires are upon us, affecting our communities, hospitals, and health delivery enterprise today. These challenges represent educational, academic, and economic opportunities that hospitalists should embrace.

\section{RECOMMENDATIONS FOR ACTION}

\section{Education and Awareness}

The first step to engagement is to promote awareness of the effects of healthcare waste. Physicians remain one of the most trusted sources of information about the health impacts of climate change. ${ }^{16}$ By educating ourselves, we can spread accurate knowledge to our patients and communities. Furthermore, we have the ability to advocate for our hospitals to follow institutions such as Kaiser Permanente and the Cleveland Clinic.

Given that hospitalists play a key role in educating students and residents, they are ideal vehicles for such dissemination. Education should begin in medical and nursing schools, where curricula detailing the importance and impact of healthcare pollution may be introduced. As hospitalists, we should champion such efforts.

\section{Measurement and Amelioration}

Second, resource use, waste production, and areas for improvement must be systematically quantified. At a national level, the Sustainable Development Unit of the National Health System (NHS) measures and reports water use, waste production, and energy consumption of the UK's healthcare sector. Consequently, the NHS has surpassed their 2015 goal of reducing their carbon footprint by $10 \% .{ }^{17}$ By establishing a baseline understanding of our carbon emissions, waste production, and water consumption, areas where physicians and hospitals can target improvement can similarly be identified.

Hospitalists appreciate the practical tradeoffs between clinical work and change efforts; thus, they are critical in establishing pragmatic policies. Physicians, often in collaboration with environmental engineers, have used evidence-based methods such as life-cycle analysis (LCA) to evaluate the environmental impacts of the pharmaceuticals and procedures that they use. ${ }^{18-20}$ An LCA is a cost-benefit analysis that examines multiple parameters of a product, namely, emissions, water use, costs, and waste production, from production to disposal. For example, an LCA of disposable custom packs for hysterectomies, vaginal deliveries, and laryngeal masks found costs savings and environmental benefits from choosing reusable over single-use items and removing unnecessary materials such as extra towels in this setting. ${ }^{18-20}$ By considering the full life cycle of a procedure, LCAs reveal important information about the value and safety of care. LCAs, along with other sustainable design strategies, are tools that can provide hospitalists with new insights for quality improvement.

\section{Public Reporting}

Numerous physicians are known for educating their communities about the impacts of pollution on health. Recently, a pediatrician brought the presence of lead in Flint's water supply to the public's attention, instigating government action and policy change. ${ }^{21}$ A group called Utah Physicians for a Healthy Environment publishes online summaries of peer-reviewed information on air pollution and health. The Huma Lung Foundation led by a pulmonologist in Chennai, India, is working with a local radio station to report daily air quality measurements along with health advisories for the city.

We must now extend this paradigm to encompass transparency about healthcare's practices and their impact on health. Indeed, the public is comfortable with this idea: a survey of 1011 respondents in the UK found that 92\% indicated that the healthcare system should be environmentally sustainable. ${ }^{22}$ One idea may be a public-facing scorecard for hospitals, akin to publicly reported quality metrics. We can look to the example of the SDU and corporations such as Apple, which publicly report their carbon emissions, waste production, water use, and other metrics of their environmental impact. By galvanizing efforts to quantify and report our impact, hospitalists have the opportunity to be a role model for the industry and increase trust within their communities.

\section{Individual Actions}

What can a hospitalist do today? First, simple measures, like turning off idle electronics, recycling appropriately, or avoiding the use of unnecessary supplies or tests, are behavioral steps in the right direction. Second, just as education, goal setting, and feedback have met success in improving hand hygiene, ${ }^{23}$ we must begin the hard work of developing programs to monitor our environmental impact. Individual hospitalist carbon scores may help intensify efforts and spur improvement. Finally, we should learn and celebrate each other's success. Renewed focus on this topic with increased reporting of interventions and outcomes is needed.

\section{CONCLUSIONS}

As hospitalists, we must look within ourselves to protect our planet and advocate for solutions that assure a sustainable future. By recognizing that a healthy environment is crucial to human health, we can set an example for other industries and create a safer world for our patients. Eliminating the harm we do is the first step in this process.

\footnotetext{
Disclosures: The authors have nothing to disclose.
}

Funding: Dr. Chopra is supported by a Career Development Award from the Agency for Healthcare Quality and Research (1-K08-HS-022835-01) 


\section{References}

1. Eckelman MJ, Sherman J. Environmental impacts of the U.S. health care system and effects on public health. Ahmad S, ed. PLoS One. 2016;11(6):e0157014. doi:10.1371/journal.pone.0157014

2. Windfeld ES, Brooks MS-L. Medical waste management-A review. J Environ Manage. 2015;163:98-108. doi:10.1016/j.jenvman.2015.08.013.

3. Environmental Protection Agency. Saving Water in Hospitals. Available at https://www.epa.gov/sites/production/files/2017-01/documents/ws-commercial-factsheet-hospitals.pdf. Accessed December 9, 2017

4. Kolpin DW, Furlong ET, Meyer MT, et al. Pharmaceuticals, hormones, and other organic wastewater contaminants in U.S. streams, 1999-2000: A national reconnaissance. Environ Sci \& Technol 2002;36(6):1202-1211.

5. Deo, RP, Halden, RU. Pharmaceuticals in the built and natural water environment of the United States. Water. 2013;5(3):1346-1365. doi:10.3390/ w5031346.

6. Lim SS, Vos T, Flaxman AD, Danaei G, et al. A comparative risk assessment of burden of disease and injury attributable to 67 risk factors and risk factor clusters in 21 regions, 1990-2010: a systematic analysis for the Global Burden of Disease Study 2010. Lancet 2013; 380: 2224-60.

7. Brook RD, Rajagopalan S, Pope CA, et al. Particulate matter air pollution and cardiovascular disease: An update to the scientific statement from the American heart association. Circulation. 2010;121(21):2331-2378. doi:10.1161/ CIR.0b013e3181dbece1.

8. Watts N, Adger WN, Ayeb-Karlsson S, et al. The Lancet countdown: tracking progress on health and climate change. Lancet. 2017;389(10074):1151-1164. doi:10.1016/S0140-6736(16)32124-9

9. Whitmee S, Haines A, Beyrer C, et al. Safeguarding human health in the Anthropocene epoch: report of The Rockefeller Foundation-Lancet Commission on planetary health. Lancet. 2015;386(10007):1973-2028.

10. Kaiser Permanente. Environmental Stewardship. Available at: https://share kaiserpermanente.org/article/environmental-stewardship-overview/. Accessed December 2, 2017

11. Health Facilities Management Magazine. Cleveland Clinic makes carbon-neutrality its newest sustainability goal. Available at: https://www. hfmmagazine.com/articles/3210-cleveland-clinic-makes-carbon-neutrality-its-newest-sustainability-goal?lipi=urn\%3Ali\%3Apage\%3Ad_flagship3_ feed\%3BHXuZOUrpQUu0OQ3RcUQqEg\%3D\%3D. Accessed December 2 2017

12. Healthcare without Harm. Metropolitan Boston Health Care Energy \& Greenhouse Gas Profile: 2011 through 2015, and 2020 Projection. Available at: https://noharm-uscanada.org/sites/default/files/documents-files/4723/
Report-Boston\%20Health\%20Care\%20Energy\%20Profile-May\%202017.pdf Accessed December 9, 2017.

13. Practice Greenhealth. Advancing sustainability in healthcare: a collection of special case studies. Available at: https://practicegreenhealth.org/sites/default/files/upload-files/hhi.case_.studies.pdf. Accessed July 22, 2017.

14. Macpherson C, Hill J. Are physicians obliged to lead environmental sustainability efforts in health care organizations? AMA J Ethics. 2017;19(12):11641173. doi:10.1001/journalofethics.2017.19.12.ecas2-1712

15. American Nurses Association. ANA's principles of environmental health for nursing practice with implementation strategies. Available at: http://www. nursingworld.org/MainMenuCategories/WorkplaceSafety/Healthy-Nurse/ ANAsPrinciplesofEnvironmentalHealthforNursingPractice.pd. Accessed December 9, 2017.

16. Maibach EW, Kreslake JM, Roser-Renouf C, et al. Do Americans understand that global warming is harmful to human health? Evidence from a national survey. Ann Glob Health. 2015;81(3):396-409. doi:10.1016/j. aogh.2015.08.010.

17. Healthcare without Harm. Reducing Healthcare's Climate Footprint: opportunities for European Hospitals \& Health Systems. Available at: https://noharm-europe.org/sites/default/files/documents-files/4746/HCWHEurope_ Climate_Report_Dec2016.pdf. Accessed May 22, 2017.

18. Campion, N, Thiel, CL, Woods, et al. Sustainable healthcare and environmental life-cycle impacts of disposable supplies: a focus on disposable custom packs. J Clean Prod. 2015;94:46-55. doi:10.1016/j.jclepro.2015.01.076.

19. Eckelman M, Mosher M, Gonzalez A, et al. Comparative life cycle assessment of disposable and reusable laryngeal mask airways: Anesth Analg. 2012;114(5):1067-1072. doi:10.1213/ANE.0b013e31824f6959.

20. Thiel CL, Eckelman M, Guido R, et al. Environmental impacts of surgical procedures: life cycle assessment of hysterectomy in the United States. Environ Sci \& Technol. 2015:49(3):1779-1786. doi:10.1021/es504719g.

21. Hanna-Attisha M, LaChance J, Sadler RC, et al. Elevated blood lead levels in children associated with the Flint drinking water crisis: a spatial analysis of risk and public health response. Am J Public Health. 2016;106(2):283-290

22. Sustainable Development Unit. Sustainability and the NHS, Public Health and Social Care system-Ipsos Mori survey. Available at: https://www. sduhealth.org.uk/policy-strategy/reporting/ipsos-mori.aspx. Accessed December 9, 2017. 23. Luangasanatip N, Hongsuwan M, Limmathurotsakul $D$, et al. Comparative efficacy of interventions to promote hand hygiene in hospital: systematic review and network meta-analysis. BMJ. 2015;351:h3728. doi:10.1136/bmj.h3728. 